\title{
The Psychosocial Impact of Epilepsy; A Study on Adult People With Epilepsy Attending Clinics In Lusaka
}

\section{Ravi Paul ${ }^{1 *}$, Sakala Joyce ${ }^{2}$ and Thankian Kusanthan ${ }^{3}$}

${ }^{1}$ Department of Psychiatry, School of Medicine, University of Zambia, Lusaka, Zambia

${ }^{2}$ University Teaching Hospital, Lusaka, Zambia

${ }^{3}$ Department of Gender Studies, School Humanities and Social Sciences, University of Zambia

\begin{abstract}
Background: Epilepsy is a chronic disease that affects different aspects of life. Few studies have measured, using validated scales, the psychosocial impact of epilepsy in a general practice setting in Zambia. them

Aim: To find out the quality of life in PWE attending clinics in Lusaka, and to find out various factors affecting

Method: A survey was undertaken of 50 subjects, with generalized or partial epileptic seizures aged 18 years or more and drawn from epilepsy clinics in Lusaka. The outcome measure was the SF-31(Quality of Life in Epilepsy Inventory-31).

Results: $38 \%$ of persons with active epilepsy had significantly low QOL due to their condition. Females had lower QOL scores than males. Patients with higher levels of education had higher scores than their counterparts with lesser education. People who had been ill for greater than 5 years had higher scores than those who had been ill for a shorter duration. Those whose caregivers had a high income from salary job had higher scores than those whose caregivers were unemployed.

Conclusion: The occurrence of seizures, even at low frequencies, is associated with psychosocial handicap, and this may remain covert in general practice. Increased impairment in QOL was observed in female, less educated patients with recent onset of seizures, and unemployed caregivers. Poor QOL in epilepsy reflects social underachievement and calls for programs to remedy their psychosocial circumstance and improve health service provisions.
\end{abstract}

Keywords: Psychosocial; Epilepsy; PWE

\section{Introduction}

Epilepsy is an episodic and chronic central nervous system disorder characterized by unprovoked, recurrent seizures that may affect physical, mental, or behavioral functioning [1]. A generalized convulsion (i.e., a grand mal fit) is the most common recognized event. The seizures usually produce brief periods of disruption, which include phenomena such as loss of consciousness, bodily distortion, injuries, unusual and often frightening psychological experiences as well as urinary and bowel incontinence [2]. Apart from the episodic seizures, there are many other ever-present factors - social, educational, cultural and so forth - which affect the quality of life (QOL) of people living with epilepsy, their families and their close social networks variably [3]. However, very little study has been done on the quality of life of PWE attending clinics in Lusaka.

Systematic studies on QOL in epilepsy from developing countries are sparse [2] and Zambia is no exception to this trend. Clinicians tend to address the patient's and family's perspective on the impact and burden of epilepsy marginally; with a goal almost exclusively on seizure control with minimal or no adverse medication effects [4]. However, people with epilepsy also have to cope with psychological and social consequences [5]. Clearly, comprehensive care needs to go beyond this goal to enable the patients and their families to lead lives as free as possible from the medical and psychosocial complications of epilepsy. A better understanding of how satisfied people living with epilepsy are with their lives is necessary if clinicians are to better help the patients lead more fulfilling lives [4].

\section{Problem Statement}

The focus of treatment of PWE by clinicians has been almost exclusively on seizure control with little or no attention paid to the psychosocial impact the condition has on the patients whereas the patients have to deal with such consequences of the disease on themselves for most part of their daily lives than they spend having the seizures themselves. This study will try to highlight this problem as postulated in the hypothesis and will find out whether PWE attending clinics in Lusaka are significantly affected in their quality of life by the condition.

\section{Rationale}

Very little study has been done on the psychosocial impact of epilepsy on PWE receiving treatment in Zambia. This has compounded the neglect on this aspect of the patients' life in the approach to treatment. This study will highlight the impact of living with epilepsy

*Corresponding author: Ravi Paul, Department of Psychiatry, School of Medicine, University of Zambia, Lusaka, Zambia, Tel: +260976744654 E-mail: ravipaul35@gmail.com

Received September 07, 2015; Accepted November 17, 2015; Published November 27, 2015

Citation: Paul R, Joyce S, Kusanthan T (2015) The Psychosocial Impact of Epilepsy; A Study on Adult People With Epilepsy Attending Clinics In Lusaka. J Epilepsy 1: 101. doi:10.4172/2472-0895.1000101

Copyright: ( 2015 Paul R, et al. This is an open-access article distributed under the terms of the Creative Commons Attribution License, which permits unrestricted use, distribution, and reproduction in any medium, provided the original author and source are credited. 
Citation: Paul R, Joyce S, Kusanthan T (2015) The Psychosocial Impact of Epilepsy; A Study on Adult People With Epilepsy Attending Clinics In Lusaka. J Epilepsy 1: 101. doi:10.4172/2472-0895.1000101

Page 2 of 6

on the quality of life which if found to be lower as postulated in the hypothesis will help guide treatment protocols formulated so that clinicians may address this aspect of treatment in their patients.

\section{Hypothesis}

Epilepsy patients currently receiving drug treatment have significantly lower quality of life. Furthermore, the most important predictors of quality of life are socio-demographic variables (e.g., sex, age, education and socioeconomic status), seizure type and severity, duration of illness, and treatment side effects.

\section{Objectives}

\section{General objective}

The objective of this study was to find out the quality of life in PWE attending clinics in Lusaka, providing a comprehensive assessment on the impact of epilepsy on their psychological well-being and social adjustment.

\section{Specific objectives}

- $\quad$ To assess the subjective QOL of subjects currently receiving drug treatment for epilepsy in stable clinical condition

- To assess the association of patients' QOL domain scores with socio-demographic variables

- $\quad$ To assess the association of patients' QOL domain scores with duration of illness

- $\quad$ Ta assess the association of patients' QOL domain scores with gender of PWE

- To assess the association of patients' QOL domain scores with age of PWE

- To assess association of patients QOL domain scores with patients' education level

\section{Materials and Method}

\section{Study population}

The study covered PWE attending clinics in Lusaka. Age - groups considered were those from 18 years; and both male and female participants were considered. The study deliberately ensured that there was adequate representation from both low and high density residential areas. Residential area and occupation were used as means of estimating socio - economic status.

\section{Sample size}

50 patients were interviewed. The sample size was estimated using the formula $n=Z^{2} \times P(1-P) / L^{2}$ where $n$ is number of subjects (sample size), $\mathrm{Z}$ is the $95 \%$ confidence interval which is estimated at $1.96, \mathrm{P}$ is the estimated proportion of PWE with low QOL estimated at 50\%, and $\mathrm{L}$ is the maximum allowable error estimated at $14 \%$.

\section{Sampling plan}

Sampling method used was "Sampling of typical cases". This involved selecting representative cases from among the people who attend the epilepsy clinics. This was done with the assistance of the doctors, clinical officers and sisters in charge of the patients. The patients were enrolled over a period of 1 month when the target size of 50 patients was achieved.

\section{Inclusion criteria}

- $\quad$ People diagnosed with epilepsy by a qualified health professional

- $\quad$ People responsible for the care of patients who could not recall the details of the disease. Should have stayed with the patient for at least 1 year.

- $\quad$ Should attend a clinic in Lusaka

\section{Exclusion criteria}

- $\quad$ People with co-existing mental or psychiatric disorders

- People in whom there may be an alternative cause for seizures, e.g., alcohol, drugs, other medical condition.

- Informants who have not lived with the patient for at least one year.

\section{Data collection}

The QOLIE-31 and seizure severity questionnaires were administered through scheduled interviews to all participants. The questionnaire included open - ended and closed ended questions.

\section{Data management and analysis}

Data was collected from completed questionnaires. Data collected from questionnaires was compiled and collated and presented in appropriate graphs and tables. Further statistical analysis was conducted on the data collected to establish existing links among the factors under question.

\section{Results}

\section{Sex distribution of PWE}

$54 \%$ of the patients interviewed were male and $46 \%$ were female.

\section{Age range of PWE}

The age range for the PWE that were interviewed was mostly falling in the range of 19 to 30 years, i.e., greater than $50 \%$, with very few people above the age of 40years (14\%).This is tabulated in Table 1 and Figure 1 below.

\section{Level of formal education}

At similar age groups, the levels of education between caregivers and PWEs were comparable. It was noted that the lower the level of education of the caregiver (CG), the lower it was for the PWE as well

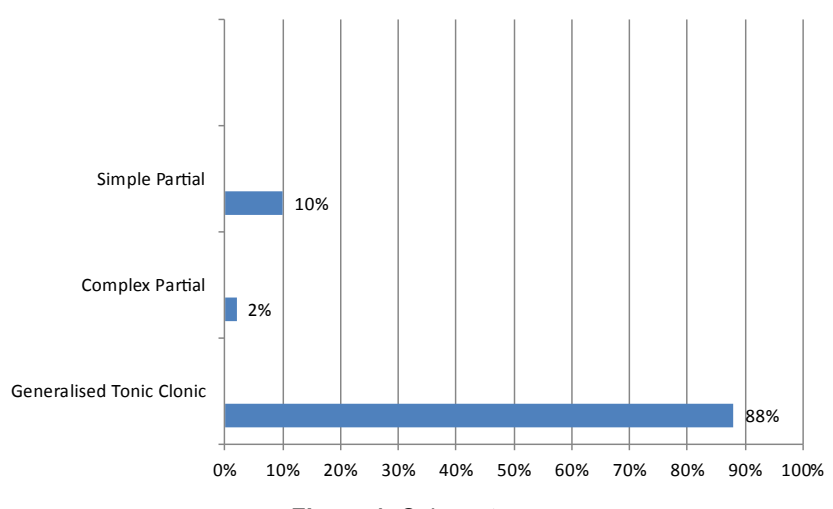

Figure 1: Seizure type. 
Citation: Paul R, Joyce S, Kusanthan T (2015) The Psychosocial Impact of Epilepsy; A Study on Adult People With Epilepsy Attending Clinics In Lusaka. J Epilepsy 1: 101. doi:10.4172/2472-0895.1000101

Page 3 of 6

\begin{tabular}{|c|c|c|}
\hline Age range in years & Frequency & Percentage \\
\hline $\mathbf{1 9 - 2 5}$ & 20 & 40 \\
\hline $\mathbf{2 6 - 3 0}$ & 14 & 28 \\
\hline $\mathbf{3 1 - 3 5}$ & 8 & 16 \\
\hline $\mathbf{3 6 - 4 0}$ & 1 & 2 \\
\hline $\mathbf{> 4 0}$ & 7 & 14 \\
\hline Total & 50 & 100 \\
\hline
\end{tabular}

Table 1: Age range of PWE.

\begin{tabular}{|c|c|c|}
\hline Education Level & Frequency & Percent (\%) \\
\hline None & 5 & 10 \\
\hline Primary & 16 & 32 \\
\hline Secondary & 21 & 42 \\
\hline Tertiary & 8 & 16 \\
Total & 50 & 100 \\
\hline
\end{tabular}

Table 2: Level of education of CG.

\begin{tabular}{|c|c|c|}
\hline Level of Education & Frequency & Percent (\%) \\
\hline None & 2 & 4 \\
\hline Primary & 20 & 40 \\
\hline Secondary & 27 & 54 \\
\hline Tertiary & 1 & 2 \\
\hline Total & 50 & 100 \\
\hline
\end{tabular}

Table 3: Level of education of PWE.

(Table 2 and 3).

\section{Residence}

Most people lived in the urban areas mostly in the high-density and middle-density areas with very few (18\%) coming from rural and semi-urban areas and none from the low-density urban areas. A much smaller number lived in the rural areas, including referrals from rural districts (Table 4).

\section{Occupation of bread winner}

As shown in Figure 2 below,most of the housedholds in which a PWE lived had bread winners who were unemplyed.They made small incomes mostly from odd jobs if they found any such as bricklaying and doing domestic chores for money where available.Another majority got their income from small businesses, low income and middle income jobs. Small businesses included selling groceries at home; having a shoe - repair shop, and so on. They were mainly low income generating ventures. Those occupied by farming were exclusively subsistence farmers. The occupation of breadwinner and residence were the measure used for socio-economic status.

\section{Seizure type}

Most of the PWE were having generalized tonic-clonic (88\%) seizures with very few experiencing some partial seizures, both simple (10\%) and complex (2\%) as shown in Figure 1 below.

\section{Duration of illness}

Most PWE had lived with the condition for over 5 years. The frequency of seizures in these patients was variable depending on the response to treatment but most of them reported not having had seizures in the previous month (Figure 3 ).

\section{Drugs}

Only $14 \%$ of patients reported experiencing mild side effects from their drug regimen which included drowsiness and weakness among others. Majority of the patients were on Carbamazepine and Phenobarbitone; mono-therapy or combined together (see Figure 4 below).

\section{QOL scores}

As illustrated in Table 5, Figure 4 the mean scores for seizure worry were lowest among PWE and the medication effects domain showed the highest scores with the other domains, i.e., overall quality of life, emotional well-being, energy/fatigue and cognitive function being in the same range of 56-62.

\section{Gender and mean QOL}

Gender had a clear impact on the QOL as seen from Table 6 and Figure 5 which show that females had less scores in all the categories reviewed.

\section{Mean QOL and age of PWE}

There is no apparent correlation between age of patient and QOL as the different components have comparable QOL scores across all the age groups. This is shown in Figure 6 below.

\section{Duration of seizures and mean QOL}

Across all groups, the seizure worry scores were lowest compared to other domains. The scores in all domains were improving with the increase in length of illness. However, the differences in scores for total QOL compared with the differences in duration of illness followed a similar trend which doesn't seem to be significantly different. Social function was much lower in PWE who had the condition for less than 2 years compared to their counterparts who had lived with the condition for longer Figure 7.

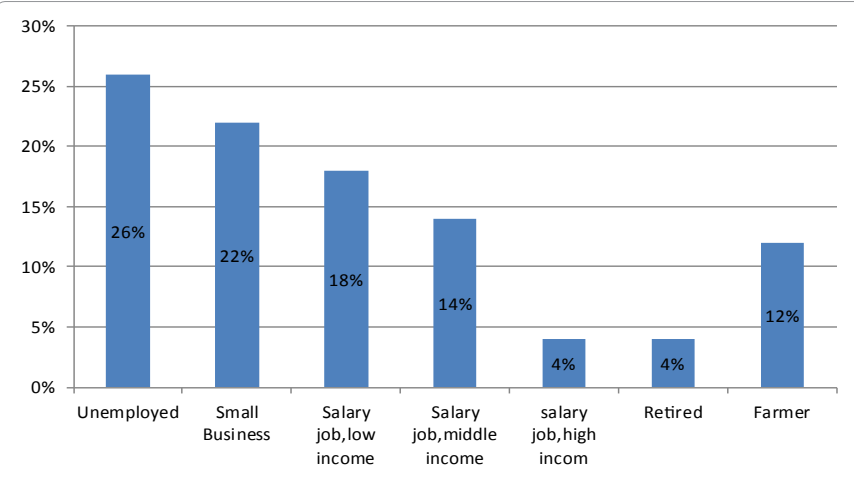

Figure 2: Occcupation of bread winner.

\section{Figure 3.Duration of Illness}

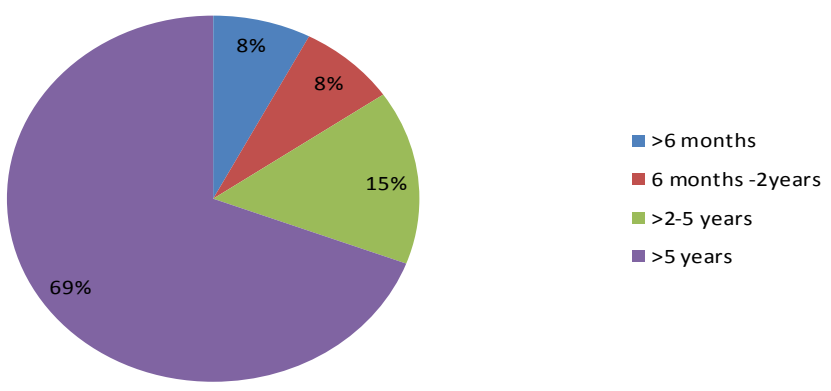

Figure 3: Duration of illness. 
Citation: Paul R, Joyce S, Kusanthan T (2015) The Psychosocial Impact of Epilepsy; A Study on Adult People With Epilepsy Attending Clinics In Lusaka. J Epilepsy 1: 101. doi:10.4172/2472-0895.1000101

Page 4 of 6

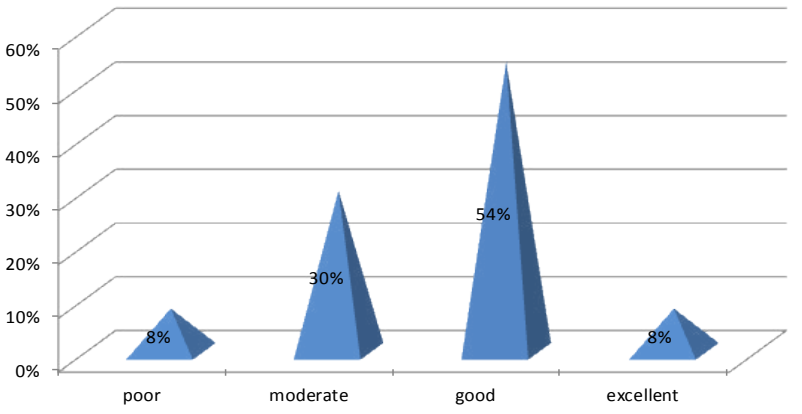

Poor- Total QOL $<40$

Moderate- Total QOL 40-60

Good- Total QOL 60-80

Excellent- Total QOL $>8$

Figure 4: Frequency of groups of quality of life (QOL) in PWE.

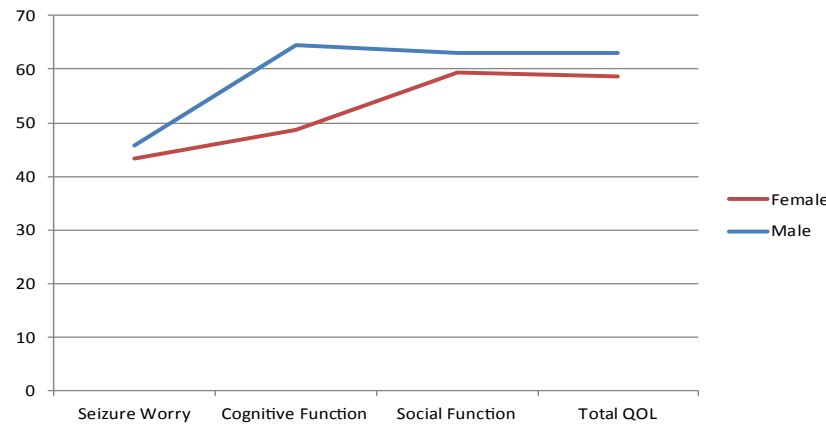

Figure 5: Mean QOL and gender.

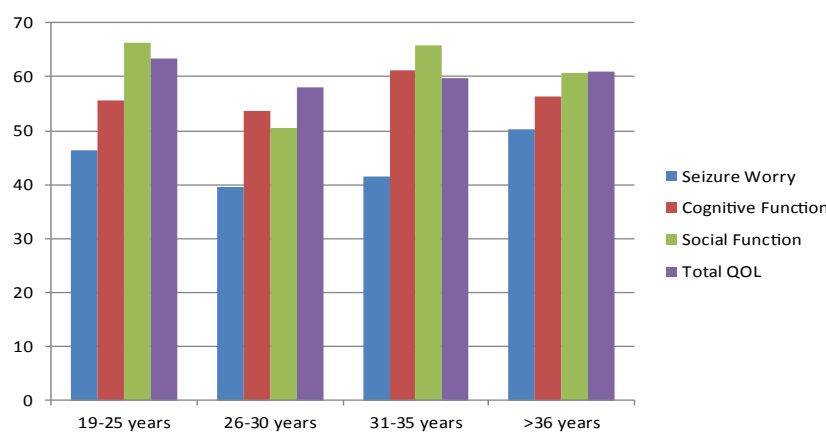

Figure 6: Mean QOL and age of PWE.

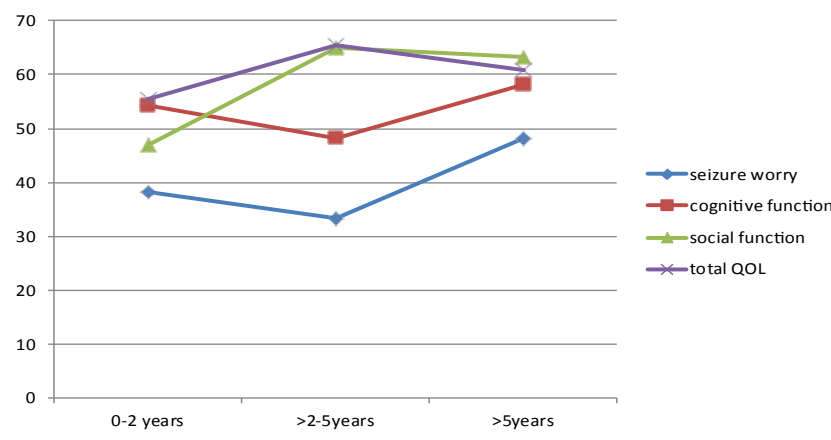

Figure 7: $\mathrm{QOL}$ and duration of illness.

\begin{tabular}{|c|c|c|}
\hline Residence & Frequency & Percent \\
\hline Rural and Semi-urban & 9 & 18 \\
\hline Urban High-Density & 24 & 48 \\
\hline Urban Middle-Density & 17 & 34 \\
\hline Total & $\mathbf{5 0}$ & $\mathbf{1 0 0}$ \\
\hline
\end{tabular}

Table 4: Residence of PWE.

\begin{tabular}{|c|c|c|c|}
\hline Scales & Score (Mean) & $\begin{array}{c}\text { Standard } \\
\text { Deviation(Sample) }\end{array}$ & $\begin{array}{c}\text { Standard } \\
\text { Deviation(Population) }\end{array}$ \\
\hline Seizure Worry & $44.58 \pm$ & 27.23 & 26.96 \\
\hline $\begin{array}{c}\text { Overall Quality } \\
\text { Of Life }\end{array}$ & $59.68 \pm$ & 26.11 & 25.85 \\
\hline $\begin{array}{c}\text { Emotional Well- } \\
\text { being }\end{array}$ & $62.40 \pm$ & 20.82 & 20.61 \\
\hline $\begin{array}{c}\text { Energy/Fatigue } \\
\text { Cognitive } \\
\text { Functioning }\end{array}$ & $58.40 \pm$ & 22.68 & 22.46 \\
\hline $\begin{array}{c}\text { Medication } \\
\text { Effects }\end{array}$ & 56.08 & 25.61 & 25.36 \\
\hline $\begin{array}{c}\text { Social } \\
\text { Functioning }\end{array}$ & 61.13 & 25.80 & 25.54 \\
\hline QOL Total & 60.96 & 15.60 & 24.21 \\
\hline
\end{tabular}

Majority of people were found to have a good quality of life with very few having extremes i.e. poor and excellent quality of life. This is shown on figure 4 below.

Table 5: SF-31 Scores in PWE.

\begin{tabular}{|c|c|c|}
\hline Sex & Male & Female \\
\hline Seizure Worry & 45.76 & 43.31 \\
\hline Cognitive Function & 64.48 & 48.65 \\
\hline Social Function & 63.02 & 59.38 \\
\hline Total QOL & 63.11 & 58.55 \\
\hline
\end{tabular}

Table 6: Mean QOL and gender.

\section{QOL and socio-economic status}

Figure 8 shows that there was a significantly big increase in scores for all domains in those whose breadwinners had a high income salary job. However, PWE with other sources of income had similar trends in scores for cognitive and social function as well as total QOL. The seizure worry scores were low compared to other domains for all the groups and were lowest among PWE who are cared for by farmers.

\section{QOL and level of education of PWE}

According to Figure 9 and 10 PWE who had attained tertiary education had significantly high scores in social \& cognitive function as well as total QOL compared to the others. However, they had the lowest scores in the domain of seizure worry with those who had no education at all having the highest scores in this category. All the other domains were comparable among the different education levels except for tertiary level which has been explained above.

\section{Discussion}

Epilepsy is a chronic and serious neurological disorder with multifaceted uncertainties and stigmatization which have significant negative role in the QOL of those afflicted by the disorder. Although epilepsy is a controllable disorder, treatment can be delayed for most families in rural areas because of the inaccessibility of specialist neurological assessment facilities. Although physical disability may occur in PWE due to associated disease (i.e., a seizure disorder in conjunction with cerebral palsy), as a consequence of a seizure (i.e., a fracture), or indirectly, due to inability to participate in certain 


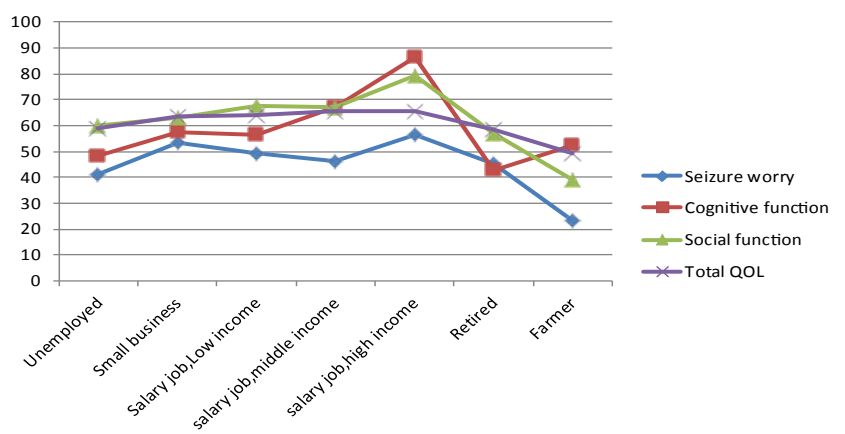

Figure 8: QOL and occupation of bread winner.

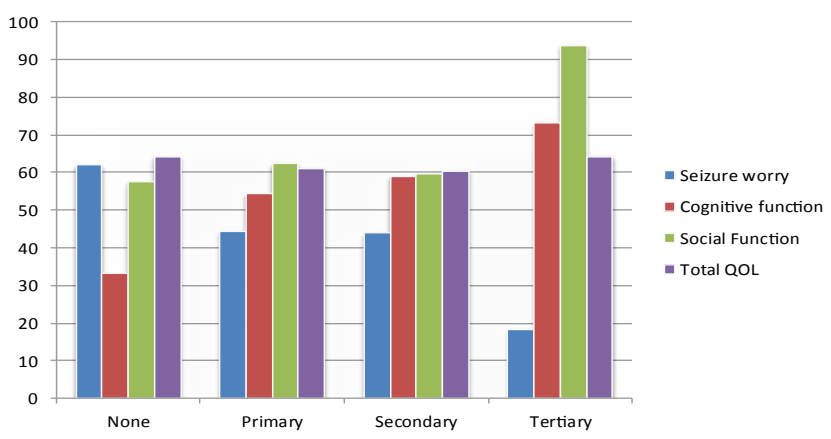

Figure 9: QOL and education level of PWE.

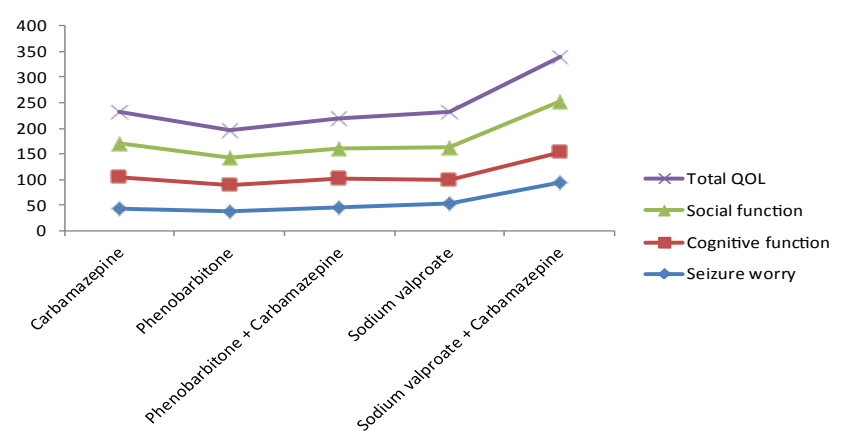

Figure 10: Mean QOL and drugs.

physical activities because of legal restrictions on driving, epilepsy had sometimes been termed the "silent disability" because PWE usually do not have obvious physical impairments

The Quality of Life in Epilepsy Inventory-31 (QOLIE-31) contains seven multi-item scales that tap the following health concepts: emotional well-being, social functioning, energy/fatigue, cognitive functioning, seizure worry, medication effects, and overall quality of life. A QOLIE-31 overall score is obtained using a weighted average of the multi-item scale scores.

In this research 50 patients were studied. $88 \%$ had grand-mal seizures, $10 \%$ with simple partial seizures while only $2 \%$ had complex partial seizures with the majority (72\%) having had the condition for over 5 years. $54 \%$ of these were male and majority of the patients were urban dwellers mostly from high and medium density residential areas (82\%). They were predominantly young people mostly in the reproductive age group of $19-35$ years (84\%) which is also most productive economically. $94 \%$ of the PWE had at least been through primary with $54 \%$ having some level of secondary education. This was comparable to the caregiver level of education where $42 \%$ had some level of secondary education. The most common drug used was carbamazepine (38\%) followed by phenobarbitone (28\%). About $26 \%$ of the patients were treated with two drugs and up to $74 \%$ received monotherapy.

Educationally, the epileptic patients suffered notably in that few attained either high school certificate or university education. Even those who had attained primary education did not obtain the primary certificate because they had to quit before completion of the primary level. Educational difficulties were attributed mainly to lack of financial support, seizures, embarrassment and personality problems. Similar findings were reported by Lennox et.al. (1946), rodin et.al (1972), Holdsworth and Whitmore (1974), and Myklebust (1979). Interestingly, the level of education of the PWE was comparable to the care givers level of education. These could explain the attribution of financial support to lack of education as most of the care givers had little education and qualifications to secure them stable high income jobs.

The level of education of the care giver translated into the socioeconomic status of the patients. It is no wonder that most PWE were living in low socioeconomic settings, mostly from high and middle density urban areas. The income potential of the caregivers was mostly poor in that most of them were not employed but relied on small businesses and odd jobs, while the few that were employed mostly had low income jobs. This contributed to the reduction in quality of life of the PWE as shown in results above.

The level of reported side effects of anti-epileptic drugs was not particularly high. Most patients were happy with their drugs, reporting improvement in terms of seizure frequency with drug intake. Very few (14\%) reported mild side effects to some drugs most of which were tolerable and viewed to be not significant by the patients compared to the benefit of relief from reduced seizure frequency. However, PWE have to contend with side effects of anti-epileptic drugs which may be both cognitive and physical. Side effects may be more common with polytherapy and are apparently less common with newer drugs. Furthermore, PWE on phenobarbitone had lower QOL in all aspects reviewed compared to these on carbamazepine and those on sodium valproate. Those on combination therapy of sodium valproate and carbamazepine had the highest scores among them all. All major AEDs have adverse cognitive effects, including reduced attentiveness, impoverished memory, and mental slowing, and those patients with more cognitive impairment also have more psychosocial problems.

The QOL scores in the majority of patients were good, but there was another significantly large group with poor to moderate QOL. This rather poor quality of life could be accounted for by the disease chronicity, their social underachievement, and the noted impact of lifelong social stigma with family members having to care for them when all hands were needed to manage the demands of making a living.

Higher QOL was associated with male gender, duration of illness greater than 5 years, higher education attainments and higher level of employment of the care giver. It is reasonable to suggest that these factors increase the potential for awareness of disease, social support and the use of positive coping methods. There was no apparent correlation between age of the patient and their quality of life. Baker and others also recently found that there is no significant correlation between increasing age and QOL [6]. An improvement in socio- 
economic status will therefore help patients so we must take this into consideration when trying to help patients. Higher QOL is also possibly related to positive psychological response to the challenges of life i.e. the human capacity to find positive meaning in adverse circumstances which is linked with life satisfaction and coping $[7,8]$.

Shakarishvilli et.al found that female gender was found to be a major determinant of the QOL in PWE [9]. Two Indian studies reported similar findings $[10,11]$. In a European study on the QOL with epilepsy, female respondents had poorer energy/vitality, physical functioning, mental and general health. This study also confirms these studies because females were also found to have a lower quality of life in all components compared to their male counterparts.

All the people interviewed were not driving. There may be many factors to which this could be attributed including poor socioeconomic status and unemployment among PWE which extended even to the transport sector where they could not be employed as drivers. It is known that driving accidents are more common for epileptic persons than in the general population [12-15]. This may suggest that licensing regulations or voluntary restraint were successful in eliminating potentially dangerous epileptic drivers. It has been shown that careful selection of which epileptic patients are permitted to drive does in fact improve driving record up to normal levels.

\section{Conclusion}

Females, less educated patients with recent onset of seizures, and unemployed care givers had lower QOL scores. Findings call for improved provision of services, and for the clinician to consider that protracted years of seizure and social stigma can render the patient vulnerable to diminished functional living [16].

The following will undoubtedly help epileptic patients enhance their QOL: to manage patients with epilepsy to become seizure free through treatment with minimal side effects, to gain acceptance and validity from the community, to secure satisfying occupations and to pursue higher paid careers. Therefore, it is our solemn duty to take into account the quality of life as a determinant for better treatment $[17,18]$.

\section{Challenges and Limitations}

- Collecting data was quite difficult as the questionnaires were long; and patients needed a lot of time with translation and explanations how to score their answers so it became very tiring and hence difficult to ask the questions thoroughly.

- $\quad$ Language barriers; the questionnaire was designed in English, but most participants could only speak Bemba or Nyanja. Therefore some questions may have been distorted during attempts to translate.

- Finding time to collect data during full time academic activities was difficult.

- Participants were interviewed during the clinic session, which was about 2.5 hours long; thus the window of opportunity for data collection was very short.

\section{Recommendations}

- The clinicians involved in treatment of PWE may employ the tools for assessing QOL in order to evaluate the patients' response to instituted treatments, including possible side effects. This will help in treating the patient as a whole human being, taking into account all aspects of their lives in treatment choices
- $\quad$ PWE and their care givers must be encouraged to attend school and appropriate authorities enlightened about the condition so that they may make the school environment as comfortable as possible for PWE.

- Clinicians must endeavour to give as much information as possible about epilepsy to the PWE and their care givers so that they may take an active part in the control of their condition; this will make them make them feel more in control of their lives.

- $\quad$ More research must be done on different aspects of epilepsy in order to understand it in order to improve its management which will ultimately enable PWE have better QOL than they do.

\section{References}

1. Baker GA, Jacoby A, Chadwick DW (1996) The associations of psychopathology in epilepsy: a community study. Epilepsy research 25: 29-39.

2. Baker GA (2002) The Pysochosocial burden of epilepsy. Epilepsia 43: 25-30.

3. Rajabi F, Dabiran S, Hatmi ZN, Zamani G (2009) Quality of Life of Epileptic Patients Compared to General Population in Tehran. Acta Medica Iranica 47: 75-78

4. Ohaeri JU, Awadalla AW, Farah AA (2000) Quality of life in people with epilepsy and their family care givers: An Arab experience using the short term version of WHO quality of life instrument. Saudi Medical Journal 30: 1328-1325.

5. Hills MD (2007) The Psychological and social impact of epilepsy, Neurology Asia 10: 10-12.

6. Baker GA, Jacoby A, Buck D, Brooks J, Potts P, et al. (2001) The quality of life of older people with epilepsy: Findings from a UK community study. Seizure 10: $92-99$

7. Pakenham KI, Cox S (2008) Development of benefit finding in multiple sclerosis (MS) caregiving scale: a longitudinal study of relations between benefit finding and adjustment. British Journal of Health Psychology 13: 583-602.

8. Kim Y, Schulz R, Carver CS (2007) Benefit finding in the cancer caregiving experience. Psychosomatic Medicine 69: 283-291.

9. Shakarishvilli DM (2003) Influence of clinical, demographic and socioeconomic variables on QOL in patients with epilepsy: Findings from Georgian Society. J Neurol Nerosurg Psychiatry 74: 570-573.

10. Thomas SV, Koshy S, Nair SCR, Sarma SP (2005) Frequent seizures and polytherapy can impair quality of life in persons with epilepsy. Neurol India 53 46-50

11. Agarwal P, Mehndiratta MM, Antony AR (2006) Epilepsy in India: Nuptiality behavour and fertility. Seizure 25: 594-598.

12. Commission on classification and terminology of the International league against epilepsy (1989) Proposal for revised classification of Epilepsies and Epileptic syndromes. Epilepsia 30: 389-399.

13. Hamati-Haddad A, Abou-Khalil B (1998) Epilepsy diagnosis and localization in patients antecendant childhood febril convulsions. Neurology 50: 917-922.

14. Morrell MJ (2001) The Physiological and psychological consequences of Epilepsy. Advanced studies in medicine 1: 294-301.

15. O'Donoghue MF, Goodridge DMG, Redhead K, Sander JWAS, Duncan JS (1999) Assessing the psychosocial consequences of epilepsy: a communitybased study. British Journal of General practice 49: 211-214.

16. Baker GA, Brooks J, Buck D, Jacoby A (2000) The stigma of epilepsy: a European perspective. Epilepsia 41: 98 -104.

17. World Health organization (WHO) (2005) Atlas of Epilepsy care in the world

18. Vickrey BG, Hays RD, Graber J, Rausch R, Engel J, et al. (1992) A healthrelated quality of life instrument for patients evaluated for epilepsy surgery. Medical care 30: 299-319. 